\title{
THE CALORIGENIC ACTION OF D- AND L-THYROXIN
}

\author{
By W. T. SALTER, J. LERMAN, AND J. H. MEANS \\ (From the Huntington Memorial Hospital and the Thyroid Clinic and Metabolism Laboratory \\ of the Massachusetts General Hospital, Boston)
}

(Received for publication August 14, 1934)

Evaluation of the significance of calorigenic responses obtained by the assay of constituents of the thyroid in myxedematous persons is fraught with difficulty. The questions of absorption, excretion and destruction of the material administered all intrude to plague the investigator. The rôle of physical properties such as solubility or optical activity must be identified. The possibility of enhancement of physiologic potency brought about by alteration in physical state has been mentioned in previous communications (1) (2). In the first paper of this series (1) it was shown that racemic crystalline thyroxin and optically active thyroxin polypeptide had equal calorigenic activity when given in equal iodine dosage.

To settle, if possible, the single point of the part played by optical activity the present study was undertaken. We are indebted to Professor C. R. Harington for a supply of pure crystalline $d$ - and $l$-thyroxin (3). The substances have been assayed on myxedema patients in the manner described in earlier papers (1) (2). The results are shown graphically in Figure 1. A curve which represents the average response obtained in five myxedema patients receiving $1.0 \mathrm{mgm}$. of thyroxin polypeptide (50 per cent iodine) per day by mouth is also included in this figure in order to indicate the standard response to $0.5 \mathrm{mgm}$. of thyroid iodine daily.

Special care was taken to avoid racemization of the optically active material. The weighed microcrystalline powder was dissolved in cold 0.01 normal sodium hydroxide, of which $6 \mathrm{cc}$. were used per milligram of iodine. Three cubic centimeters of the freshly prepared thyroxin solution were measured into sterile ampoules. To each ampoule was added $1 \mathrm{cc}$. of distilled water and enough fifth-normal orthophosphoric acid to bring the reaction of the solution to $\mathrm{pH} 6.5$. The ampoules were then stoppered with special "bacteriological" rubber caps, shaken to disperse the precipitated thyroxin, and heated at $80^{\circ} \mathrm{C}$. for ten minutes. They were then kept iced until used. Three or four such ampoules were prepared at once, to be used on successive days. Immediately before injection, one-half cubic centimeter of cold tenth-normal sodium hydroxide was added by means of a sterile syringe and the thyroxin again dissolved by shaking.

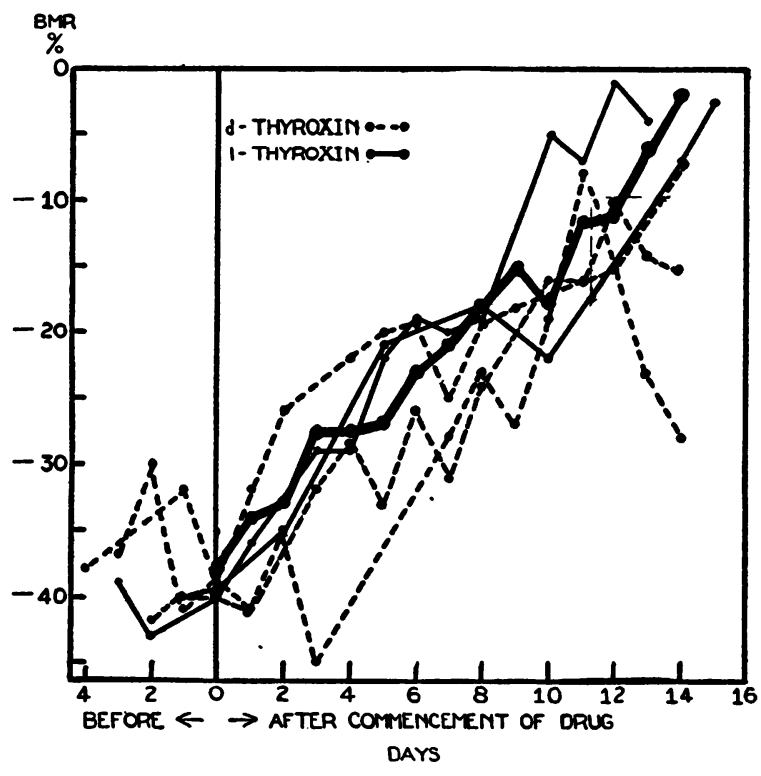

Fig. 1.

The calorigenic responses in two patients with spontaneous myxedema receiving a daily intravenous dose of $0.75 \mathrm{mgm}$. of $l$-thyroxin (light solid lines), and of three patients receiving a daily intravenous dose of $0.75 \mathrm{mgm}$. of $d$-thyroxin (interrupted lines). The solid curve represents the composite of five assays of thyroxin polypeptide given in daily oral doses containing an equivalent amount of iodine, namely $0.5 \mathrm{mgm}$.

In this way, the racemizing effects of heat, alkali, and strong acid were kept at a minimum. These precautions are as rigorous as those used by Harington and Salter (4) in the isolation of $l$-thyroxin.

Two assays were obtained with $l$-thyroxin and three with $d$-thyroxin. The subjects were all untreated cases of spontaneous myxedema, none of 
whom were used for more than one assay. Each preparation was given intravenously once daily in doses of $0.75 \mathrm{mgm}$. daily this being equivalent in iodine content to the $1.0 \mathrm{mgm}$. of the control polypeptide assays.

The two $l$-thyroxin assays and two of the $d$ thyroxin assays are sufficiently close to the control curve to be considered to represent identical responses. One of these two patients receiving $d$ thyroxin also received desiccated thyroid, 3.75 grains daily by mouth ( $0.5 \mathrm{mgm}$. organic iodine) at the end of the series of thyroxin injections. The metabolism rose from minus 15 per cent to 0 per cent in six days, but the slope of the curve remained the same. The third patient receiving $d$-thyroxin began to make a standard response, the metabolism reaching minus 8 per cent on the eleventh day, but subsequently dropped to minus 28 per cent on the fourteenth day. When desiccated thyroid 3.75 grains daily $(0.5 \mathrm{mgm}$. organic iodine), was substituted two days after the last thyroxin injection, the metabolism changed relatively little, reaching minus 18 per cent after seven days of medication. Consequently the low response yielded by this patient receiving the dextrorotatory isomer may be discounted as due to some peculiarity inherent in the patient and not in the substance assayed. These measurements seem to indicate that the response of myxedema patients to either optical isomer of thyroxin is essentially identical.

\section{COMMENT}

This series (1) (2) (4) (6) of observations was begun in an attempt to explain the high metabolic potency of thyroglobulin in which thyroxin itself may constitute only a minor portion of the total iodine. It was originally suspected that peptide linkage and optical activity (4) (7) might be the chief factors involved in the high potency of the natural hormone. As previously reported (1), thyroxin in natural peptide combination failed to show unexpectedly high activity. This result has been confirmed by observations to be reported elsewhere upon racemic glycyl thyroxin (8) kindly donated by Harington. These synthetic products embodying peptide linkage and optical activity have enabled us to analyze the effects of the two characteristics separately. Neither of these chemical relationships has been found to alter significantly the activity of thyroxin provided that absorption was ensured by parenteral administration.

It has become evident, however, that the observed potency of the drug depends to a considerable extent upon the mode of assay. For example, it has been known for a long time (9) that the intact thyroid tends to trap iodine if the latter is in excess and to withold it from the systemic circulation. Similarly Schittenhelm and Eisler have shown (10) (11) that when a single large dose of thyroxin is administered, much of the iodine is excreted in the first forty-eight hours. Such a condition is obviously abnormal, and one is constantly faced with the question: does our assay represent a physiological potency, or is it merely the expression of the net result of an experiment under complex pharmacological conditions? Assays of thyroid activity have been made both in man (1) (2) and in animals (13) by the method of massive dosage. Such procedures, we believe, induce disturbances of body mechanisms, which are foreign both to the physiological behavior of mammals and to ordinary routine clinical conditions. Such abnormally planned procedures, it would seem, have tended to mislead us not only as to the action of the thyroid hormone under normal conditions but also as to its effect in the usual cases of myxedema as treated in present-day clinics.

Criticism on the grounds mentioned above is avoided by the method of assay here employed, which consists of the administration of a uniform daily dose of thyroid material at a rate calculated to restore the patient to a nearly normal state in some two weeks' time. This is a therapeutic program in use in many clinics at the present date. Certain it is, that this procedure resembles the usual clinical methods of thyroid therapy more closely than does the administration of massive single doses of the drug.

The results here reported are at variance with assays in the literature which show that the levorotatory isomer is several times as potent as the dextrorotatory. Of these researches we select for comment only one, that of Gaddum (13), because the assays were made with the identical preparation used by us and supplied by Harington. His observations, made upon normal rats to which single large doses of thyroxin ( $d$ - or $l$-, re- 
spectively) were administered, showed the $l$ - compound to be about three times as active as the $d$ isomer. The difference between his results and ours, we believe, may be explained upon several grounds. In the first place, the animals possessed an intact thyroid apparatus which might trap newly-administered iodine, and which might fluctuate in activity. Secondly, the drug was administered in a single massive dose (4 to $10 \mathrm{mgm}$. of thyroxin per kilo) as against our daily dose in man of $0.01 \mathrm{mgm}$. per kilo). so that rates of excretion and destruction of the drug would play important rôles in determining the duration and height of the responses. In fact, according to Gaddum's own data, the discrepancy between the two isomers became smaller with smaller doses than with larger doses. Whether the difference in species contributed to the discrepancy we do not know. We merely conclude that such observations, however valid as laboratory experiments, can not be expected to apply quantitatively to the reaction of the human case of myxedema.

\section{CONCLUSIONS}

When assayed by a method designed to reproduce approximately both physiological and ordinary clinical conditions, $d$ - and $l$-thyroxin were found to have essentially identical potencies in relieving human myxedema.

This fact lends additional support to the thesis that the high potency of thyroglobulin is not due to a super-active form of thyroxin.

\section{BIBLIOGRAPHY}

1. Salter, W. T., Lerman, J., and Means, J. H., The calorigenic action of thyroxin polypeptide. J.Clin. Invest., 1933, 12, 327.
2. Means, J. H., Lerman, J., and Salter, W. T., The rôle of thyroxin iodine and total organic iodine in the calorigenic action of whole thyroid gland. J. Clin. Invest., 1933, 12, 683.

3. Harington, C. R., The resolution of $d l$-thyroxine. Biochem. J., 1928, 22, 1429.

4. Harington, C. R., and Salter, W. T., The isolation of $l$-thyroxine from the thyroid gland by the action of proteolytic enzymes. Biochem. J., 1930, 24, 456.

5. Lerman, J., and Salter, W. T., The maintenance requirements of myxedema patients. Clinical and chemical assay of commercial thyroid preparations. J. Pharmacol. and Exper. Therap., 1934, 50, 298.

6. Lerman, J., and Salter, W. T., The calorigenic action of thyroid and some of its active constituents. Endocrinology, 1934, 18, 317.

7. Harington, C. R., and Randall, S. S., Observations on the iodine-containing compounds of the thyroid gland. Isolation of $d l-3: 5$-di-iodotyrosine. Biochem. J., 1929, 23, 373.

8. Ashley, J. N., and Harington, C. R., Some derivatives of thyroxine. Biochem. J., 1928, 22, 1436.

9. Marine, D., and Rogoff, J. M., How rapidly does the intact thyroid gland elaborate its specific iodinecontaining hormone? J. Pharmacol., 1917, 9, 1.

10. Schittenhelm, A., and Eisler, B., Uber die Resorption und Ausscheidung des Thyroxins beim schilddrüsengesunden, beim schilddrüseninsuffizienten und beim hyperthyreotischen Menschen. Ztschr. f. d. ges. exper. Med., 1932, 80, 580.

11. Schittenhelm, A., and Eisler, B., Uber die Jodausscheidung beim myxödematösen Menschen nach fortgesetzter Thyroxinzufuhr. Ztschr. f. d. ges. exper. Med., 1933, 86, 299.

12. Thompson, W. O., Nadler, S. B., Taylor, S. G., III, and Thompson, P. K., The calorigenic action of various thyroid derivatives. J. Clin. Invest., (Proc.) 1934, 13, 690.

13. Gaddum, J. H., Quantitative observations on thyroxine and allied substances. II. Effects on the oxygen consumption of rats. J. Physiol., 1929-30, 68, 383. 